\title{
Difficulties in teaching the second foreign (English) language to students studying oriental language as their major at NEFU, Yakutia, Russia
}

\author{
Aleksandra Ivanova* \\ North-Eastern Federal University, 58 Belinsky str., Yakutsk, 677000, Russia
}

\begin{abstract}
The Far Eastern Federal District of Russia, including the Republic of Sakha (Yakutia), is located in close proximity to the Asia-Pacific region, which explains the demand in specialists who know oriental languages. One of the oriental languages (Japanese, Chinese or Korean) is studied at the head university of the republic, and English is the language of business communication. In secondary educational institutions of Yakutia, English is the first foreign language, and students study it as a second foreign language in the university. The goal of this study is to identify the main difficulties of learning English as a second foreign language by bilingual students studying the oriental language (Japanese, Chinese or Korean) as their major. The study analyzed domestic and foreign literature, professional educational programs of the North-Eastern Federal University in Yakutsk, characteristics of students from the indigenous population of Yakutia. It was substantiated that the more difficulties in mastering the subject, the stricter the requirements for mastering the educational material.
\end{abstract}

\section{Introduction}

In modern Russian society and the higher education system of the Russian Federation, interest in the course "Foreign Language" has increased due to the changes in the world community and the social life of the country. The university graduate must be fluent in two or more foreign languages, which is a reflection of the general European trend in education [1].

The process of modernizing the Russian education system following the European standards began with the Bologna Declaration signed by Russia in September 2003. The Russian Federation has undertaken a number of obligations to reform the education system $[2,3]$.

In the last decade, a number of legislative measures in the field of education have been accepted in Russia. For instance, the federal law "On Education in the Russian Federation" (December 2012) specifies the requirements for foreign language training of future specialists. According to the section "Basic principles of state policy and legal regulation of relations in the field of education", higher professional educational institutions must create conditions for the student to master foreign languages (Article 3, paragraph 5) in order to combine the education systems of the Russian Federation with the education systems of foreign countries. The law addresses the issues of free integration into a multicultural space and free access to various resources of European countries for the professional development of the individual and the provision of highly qualified specialists [4].

\section{Materials and methods}

The problem of learning a second foreign language is often associated with the problem of bilingualism. According to V.N. Yartseva, bilingualism is "the ability of an individual, or a people as a whole to communicate in two languages" $[5,5]$. L.V. Shcherba distinguishes two types of bilingualism: the first is pure bilingualism, two languages are never used simultaneously and are completely isolated from each other (communication at school or at work occurs in one language, and at home, with the family, in another language); the second type of bilingualism is mixed, both languages are used in speech at the same time, creating a single language (all family members and acquaintances are in the same social group, but at the same time, being in a different environment, work or informal, meeting in different places, they mix languages when communicating with each other) [6].

This phenomenon is typical in the Republic of Sakha. According to the All-Russian Population Census in Yakutia of 2010, a total of 985,528 inhabitants of the region were documented. Of these, the number of the indigenous population (Yakuts, Dolgans, Yukagirs, Evens, Evenks, Chukchi) is 506 428 people $(54.1 \%)$; most of them indicated Yakut as their native language - $467764(92.5 \%)$. Of the total

\footnotetext{
Corresponding author: alexas6@yandex.ru
} 
indigenous population, 452967 people speak Russian $(89.4 \%)$ [7].

J. Flege, I.R.A. Mackay, and T. Piske argue that bilinguals can be those who move to a foreign country and learn its language. Those who have lived in a new country for several years have a dominant first (native) language and a strong foreign accent in their second (local) language. Bilinguals who have a dominant second (local) language suppress the influence of their first (native) language system when pronouncing sentences in the second language, i.e. they can avoid phonetic interference of the first language [8].

The overwhelming majority of the North-Eastern Federal University students studying oriental language as their major in Yakutia are Yakuts brought up in bilingual families and fluent in two languages: Russian and Yakut (native). In the household, the Yakut language is more often used, and in the business area people speak Russian. In addition, they study two foreign languages at the university.

According to N.V. Baryshnikov, a student who speaks two or three foreign languages is able to gain access to scientific and technological progress and enter the international educational and economic sphere. In his point of view, educational process of learning a second foreign language at school is the multilingual education based on the native, first and second foreign languages, when the second foreign language forms an artificial triglossy (trilingualism) and a multicultural context. All three languages form a field of linguistic knowledge that changes the system and logic of teaching all disciplines of the language cycle [9].

B.A. Lapidus is of the same opinion. Firstly, the second foreign language is the third language after the native and foreign, and, secondly, much less academic hours are devoted to its study [10]. Following N.V. Baryshnikov and B.A. Lapidus, A.V. Voinova believes that teaching a second foreign language in a linguistic university is carried out in conditions of contact between three languages (native, first and second foreign languages). Therefore, she highlights the following features of this process (Fig. 1) [11].

Following A.A. Prokhorova, knowledge of several languages, individual multilingualism, the use of several languages in a certain linguistic situation are characterized by the term "multilingualism". "In the conditions of a non-linguistic higher school, "multilingualism of students" is determined, which is determined as a process and result of the conscious mastering of two (trilingualism), three (tetralinguism) and more foreign languages [12: p. 21]. The same definition applies to students of the language university.

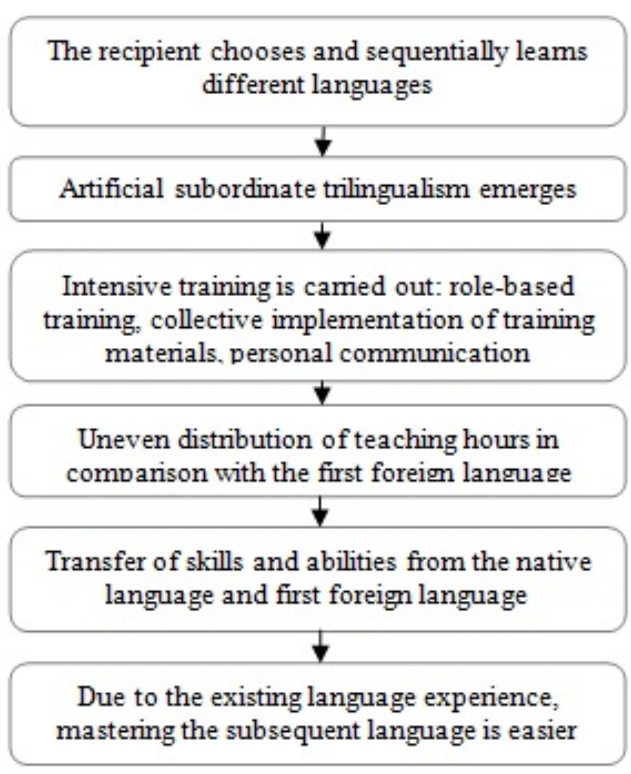

Fig. 1. Features of teaching a second foreign language.

\section{Results and discussion}

The Far Eastern Federal District, including the Republic of Sakha, is located near the Asia-Pacific region, which explains the demand for specialists speaking oriental languages. In this regard, one of the oriental languages (Japanese, Chinese or Korean) is studied as the first foreign language at the head university of the republic, and English is the language of business communication.

In this context, three phenomena arise: 1) the first foreign language in the curriculum (Japanese, Chinese or Korean) is in fact the fourth language studied; 2) the first mastered foreign (English) language becomes the second most important at the university; 3) as a result, students develop both trilingualism (native FL 1 - FL 2) and multilingualism (native - Russian FL 1 - FL 2).

Much more academic time is devoted to learning the main oriental foreign language than English. According to S.K. Efimova, a researcher on teaching Japanese to bilingual students from the indigenous peoples of Yakutia, there are some difficulties in teaching [13].

1. Methodological difficulties in teaching:

- lack of uniform approaches to teaching the Japanese language in the Russia;

- learning from A0;

- decreasing motivation to study among students who enrolled solely as a result of interest in the Japanese subculture.

2. Language learning difficulties:

- phonetics: accentuation, intonation, the presence of sounds that have no analogues in the Yakut and Russian languages;

- a grammatical system that is different from European and Turkic languages, which is characterized by a large number of postpositions, 
ellipsis, vocabulary, direction of action, forms of politeness;

- stylistic variety: four variants of the literary language (book-written, book-oral, spoken-spoken and spoken-written);

- hieroglyphic writing: one hieroglyph can have 8 ways of reading, consist of 24 lines, similar elements in hieroglyphs; a vocabulary characterized by multiple homonymy, onomatopoeia, a large number of cliché phrases, differences in gender speech, and variant spelling of words;

- three conversational styles (neutral, neutral polite, polite);

- reading: no inter-word spaces, vertical organization of text from right to left.

It is also worth considering that the first foreign (English) language learnt in a secondary educational institution, along with the native and Russian languages, which forms trilingualism, is becoming a second foreign language at NEFU.

Taking into account the demand for foreign languages and the peculiarity of students of the oriental branch, some difficulties can be identified (Fig. 2):

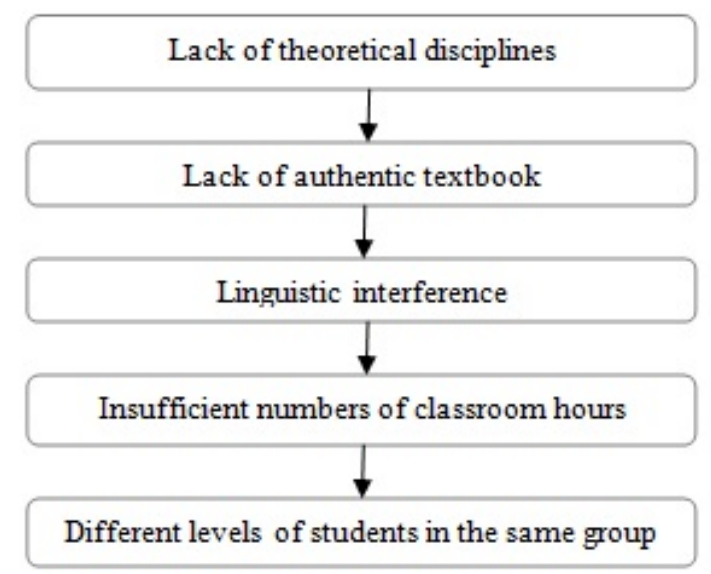

Fig. 2. The main difficulties in teaching a second foreign (English) language at a language university.

These difficulties are due to the peculiarities of students studying foreign languages, who are bilingual students, natural speakers of their native (Yakut) language and the second interethnic (Russian) language. The following features can be identified. It is presented at figure $3[14,15]$ :

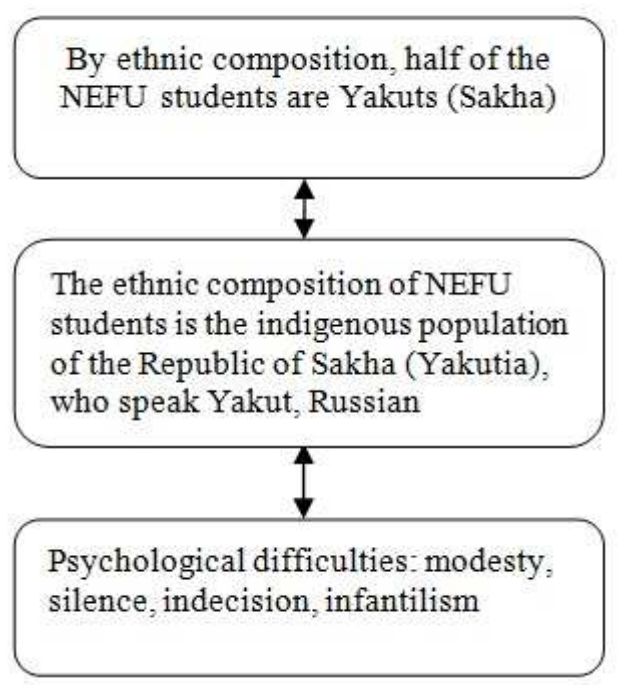

Fig. 3. Features of bilingual NEFU students from the indigenous inhabitants of Yakutia.

When teaching the second foreign (English) language, bilingual students must take into account their ethnicity $[16 ; 17 ; 18 ; 19]$. In Bashkortostan, the basic plan is being successfully implemented in the system of federal and republican education, introduced from 1993-1994, with a national-regional component in 20 variants, taking into account ethnic, socio-economic characteristics, the specifics of schools, cultural traditions of the people, life attitudes, professional plans and interests of students [20].

A number of researchers in the field of YakutRussian bilingualism (I.T. Artemiev, V.V. Grigorieva, E.D. Nelunova, V.N. Nikitina, M.M. Fomin) note that in Yakutia "the multilingual multicultural education is implemented in two main aspects - in the revival of languages and cultures of the peoples of the North, as well as in the implementation of teaching intercultural communication in the context of teaching Yakut, Russian and foreign languages and cultures. These two aspects are interrelated and mutually influence each other and represent two sides of a single process" [21, 82].

M.M. Fomin claims that there are four types of bilingualism in Yakutia, according to the classification of N. V. Imedadze (Fig.4) [22, 89].

However, "there are no studies on the methodology of teaching foreign languages in line with the specifics inherent in various Russian regions and the indigenous peoples" [23, 137].

A frequent phenomenon among first-year bilingual students of a language university is the multi-level of students (from A1 to B2) in the second foreign (English) language. This is due to the training for the Unified State Exams (Russian, English and Literature), taken as entrance examinations for admission to the Department of Oriental Languages. Other exams may score better than English. This tendency may depend on the insufficient development of the curriculum ignoring the specifics of bilingual students. Tasks of the complex level of the Unified 
State Exam (USE) are focused on the B2 level [24, 25].

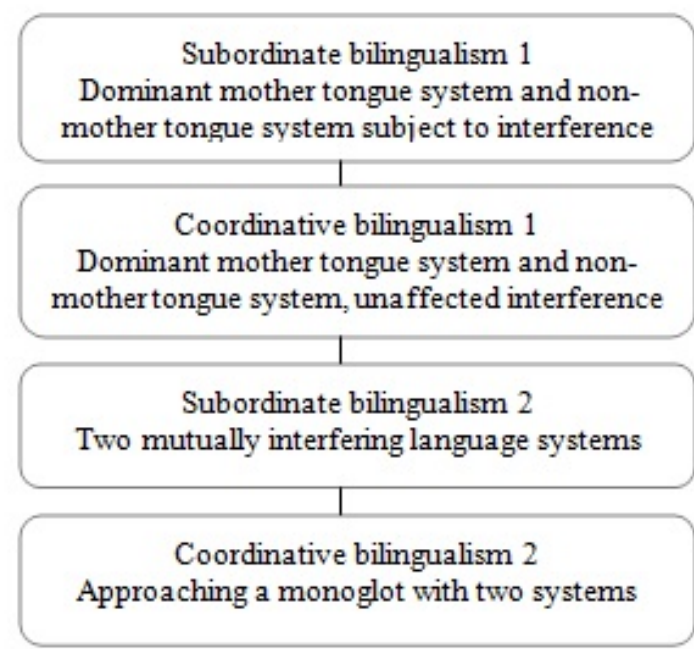

Fig. 4. Types of bilingualism in Yakutia

In learning a second foreign language, the interference of the familiar language is typical, which is more of a psychological aspect [26]. According to N.V. Bagramova, under polylingualism, the role of interference in the educational process rises with an increase in the number of languages studied [27].

Lack of foreign and domestic educational and methodological complexes, textbooks and teaching aids in English as the second foreign language for those who continue to study. There are domestic and foreign educational publications only for learning English as the first foreign language and lack of English books for those who continue to study English as a second foreign language.

There are no theoretical subjects related to the study of a second foreign language, such as theoretical grammar, theoretical phonetics, regional studies and other disciplines in the curriculum of the main professional educational program, means that proficiency in a second foreign language is inadequate, despite its good practical mastery. Moreover, if the second language is not a second specialty, it is possible to introduce a compulsory or elective discipline into the curriculum which will combine everything about the culture of Englishspeaking countries

The number of academic hours of learning English as a second foreign language has been reduced. In the working curriculum of educational programme "Foreign Philology (Japanese / Chinese / Korean language and literature)" on Federal State Educational Standard 3+ 45.03.01 Philology, only 756 hours are allocated for learning English language, and 3672 hours - for learning the main language. Moreover, in new educational programmes "Korean language in professional activity" on FSES 3++ 45.03.01 Philology and "Intercultural communication and educational sphere in Chinese language" on FSES $3++$ 45.03.02 Linguistics reduced the academic hours for the subject "Foreign Language" - 324 hours instead of 432 (1-3 semesters); the number of hours for the subject "Practical course of the second foreign language (English)" remained unchanged for Philology students (324 hours, 5-7 semesters) but totally reduced for Linguistics students [28].

According to E.P. Zvyagintseva, if a foreign language is studied only by the first and second year students, students' foreign language skills will not be developed [29]. This will contribute to rapid regression and diversification in the academic group by the time of graduation from the university.

All these difficulties cause even greater problems in teaching English as a second foreign language at the university. Following L.V. Molchanova, with an insufficient number of classroom hours allocated for the study of a second foreign language, the requirements for the quality of developed foreign language communicative competencies increase [30]. In this case, you are forced to have time to study a large amount of educational materials in a small number of lessons.

\section{Conclusion}

Having analyzed the main difficulties in teaching a second foreign (English) language and the peculiarities of bilingual students studying oriental language as a major at NEFU, Yakutia, as a result, the requirements for mastering educational materials are increasing. Moreover, in teaching the discipline, the ethnic characteristics of students are not considered due to the lack of foreign and domestic educational literature for bilingual students who continue studying English, but as a second foreign language. As a result, the multi-level of students in one academic year (from A1 to B2) is inevitable, which complicates the learning language. The solution of these problems will be appeared in our further publications.

\section{References}

1. E.V. Sharkadi, Methodology for developing the textual competence in schoolchildren at the initial stage of second foreign language learning, $\mathrm{PhD}$ thesis (Moscow, 2013)

2. Z.Sh. Karimov, Theory and practice of institutional integration of higher professional pedagogical education based on the synthesis of external and internal components, $\mathrm{PhD}$ thesis (Ufa, 2009)

3. D.R. Sabirova, Quality assurance of continuing teacher education in the UK (second half of the 20th century), $\mathrm{PhD}$ thesis (Kazan, 2009)

4. Federal Law of the Russian Federation of December 29, 2012 No. 273-FZ “On education in the Russian Federation", retrieved from: http://www.rg.ru/2012/12/30/obrazovaniedok.html

5. V.N. Yartseva, Theory of interaction of languages and the work of U. Weinreich 
"Language contacts", Language contacts: State and problems of research, 5-12 (1979)

6. L.V. Shcherba, Language system and speech activity (Leningrad: Nauka, 1974)

7. Results of the All-Russian Population Census of 2010, retrieved from: https://sakha.gks.ru/folder/39644

8. J.E. Flege, I.R.A. Mackay, Th.Piske, Assessing bilingual dominance, Cambridge University Press. Applied Psycholinguistics, 23, 567-598 (2002)

9. N.V. Baryshnikov, Methods of foreign language teachning (Moscow: Obrazovaniye, 2003)

10. B.A. Lapidus, The main problems of the methodology of teaching a second foreign language as a specialty, Collection of scientific works on the methodology of teaching foreign languages "Questions of methods of teaching a second foreign language", 80, 4-32 (1973)

11. A.V. Voinova, Methodology for improving the foreign language socio-cultural competence of undergraduate students in teaching a second foreign language, $\mathrm{PhD}$ thesis (Nizhny Novgorod, 2013)

12. A.A. Prokhorova, Methodical system of multilingual education of students of $a$ technical university, $\mathrm{PhD}$ thesis (Nizhny Novgorod, 2020)

13. S.K. Efimova, Formation of foreign language communicative competence of bilingual students in teaching Japanese (on the example of the Republic of Sakha (Yakutia), PhD thesis (Nizhny Novgorod, 2021)

14. S.N. Pavlova, G.M. Parnikova, Features of training student translators of a second foreign language in the Republic of Sakha (Yakutia), Izvestia VGPU, 4(117), 19-24 (2017)

15. S.K. Efimova, G.M. Parnikova, Difficulties and peculiarities of students of a language university in teaching the Japanese language (on the example of the Republic of Sakha (Yakutia), World of Science, Culture, Education, 5(66), 13-16 (2017)

16. Yu.P. Zinchenko, Ethnocultural identity as a factor of social stability in modern Russia. Materials of the round table: in 2 volumes, 2 (Moscow: Moscow State University n. a. M.V. Lomonosov, 2016)

17. V.A. Slastenin, These are the pedagogical factors multicultural education. (Moscow: Prometheus, 2004)

18. L.L. Suprunova, Priorities for regional Comparative Research in the Context of Modernization of Russian Education, Bulletin of VEGU, 1 (33), 44-54 (2008)

19. F.P. Kharitonova, Analysis of pedagogical phenomena in ethnopedagogical activity in multicultural educational space, Bulletin of ChSPU n.a. Yakovlev, 1 (77), 200-205, (2013)

20. N.M. Akhmerova, Implementation of the ethnocultural approach in the professional training of a social teacher to work with a family society (Moscow: MGPU, 2003)

21. V.V. Grigorieva (ed.), Teaching foreign languages in a multilingual multicultural environment (Moscow: Publishing House of the Russian Academy of Natural History, 2015)

22. M.M. Fomin, Childhood bilingualism, The Scientific opinion, 10, 84-90 (2012)

23. G.M. Parnikova, The concept of development of educational independence of students in teaching a foreign language in a regionalethnic context (non-linguistic university), $\mathrm{PhD}$ thesis (Yekaterinburg, 2018)

24. Council of Europe, Council for Cultural Cooperation. Education Committee. Modern Languages Division. Common European Framework of Reference for Languages: learning, teaching, assessment (Cambridge: University Press, 2001)

25. Specification of control measuring materials for the 2018 unified state exam in foreign languages (November 10, 2017) (Moscow, Russia. Federal Institute for Pedagogical Measurements, 2017)

26. L.V. Molchanova, Teaching a second foreign language in the context of the formation of functional multilingualism in a language university (on the example of the Japanese language), $\mathrm{PhD}$ thesis (Ryazan, 2009)

27. N.V. Bagramova, On the role of the methodology of teaching a second foreign language in the formation of a polylingual personality, Collection of scientific works "Herzen's readings. Foreign languages", 481484 (2020)

28. Working curriculum of educational programmes on FSES 3+ 45.03.01 Philology, Foreign Philology (Japanese / Chinese / Korean language and literature), FSES 3++ 45.03.01 Philology, Korean language in professional activities, 45.03.02 Linguistics, Intercultural communication and educational sphere in Chinese language (2021)

29. E.P. Zvyagintseva, Improvement of foreign language training of students on the basis of an integrative developmental approach, $\mathrm{PhD}$ thesis (Moscow, 2014)

30. L.V. Molchanova, Teaching a second foreign language in the context of functional multilingualism in a language university (on the example of the Japanese language): thesis. (Ryazan, 2009). 